\title{
Efeito da associação de sabor e música sobre o estado de ânimo de crianças ${ }^{1}$
}

\author{
Effect of the association of taste and music \\ on the mood of children
}

\author{
Viviane Freire BUENO \\ Niélsy Helena Puglia BERGAMASCO²
}

\begin{abstract}
Resumo
Este estudo teve como objetivo avaliar como sabor e música exercem efeito sobre o estado de ânimo de crianças. Participaram 83 crianças de 5 a 10 anos de idade e de ambos os sexos. A tarefa dos participantes consistiu em experimentar o sabor de soluções doce e amarga na ausência de música e na presença de músicas pré-qualificadas como alegres e tristes, e depois, julgar o estado de ânimo decorrente da experimentação. O julgamento do estado de ânimo das crianças se modificou quando o sabor era amargo e as músicas eram alegres, caso em que o estado de ânimo se alterou de triste para alegre; quando o sabor era doce e as músicas tristes, o estado de ânimo passou de alegre para triste. Futuros trabalhos podem observar crianças realizando tarefas que apresentem contextos de alimentos reais associados à estimulação musical.
\end{abstract}

Unitermos: Música. Percepção auditiva. Percepção do paladar. Psicologia da criança.

\begin{abstract}
The aim of this study was to examine how taste and music exert an effect on the state of mind of children. Eighty-three children were assessed, both male and female, between the ages of five and ten. The participants were asked to taste both sweet and bitter solutions in the absence of music and in the presence of music rated as happy and sad, and afterwards, to judge the state of mind resulting from the experiment. The judgment of the children's state of mind changed in the presence of a bitter taste and happy music, in which case the state of mind changed from sad to happy. In the presence of a sweet taste and sad music, the mood changed from happy to sad. Future experiments could evaluate children carrying out tasks that present contexts of actual items offood in association with musical stimulation.
\end{abstract}

Uniterms: Music. Auditory perception. Taste perception. Child psychology.

\section{$\boldsymbol{\nabla} \mathbf{\nabla} \boldsymbol{\nabla}$}

1 Artigo elaborado a partir da dissertação de V.F. BUENO, intitulada "Efeito da associação de sabor e música sobre o julgamento gustativo e o estado de ânimo de crianças". Universidade de São Paulo, 2006. Apoio financeiro: Fundação de Amparo à Pesquisa do Estado de São Paulo, processo n 04/11911-5.

2 Universidade de São Paulo, Instituto de Psicologia, Departamento de Psicologia Exprimental. R. Prof. Mello Moraes, 1721, Cidade Universitária, 05508-030, São Paulo, SP, Brasil Correspondência para/Correspondence to: V.F. BUENO. E-mail: <vfbueno@usp.br>.

Agradecimento às crianças que participaram dos experimentos, a Maura G. Lapa e Silvia N. Elian, por terem realizado a análise estatística do estudo, a Marcelo F. Costa, pela revisão dos gráficos, a Rafael F. Bueno. 
É possível realizar inferências a respeito do estado de ânimo de uma criança quando esta for exposta à estimulação gustativa ou auditiva, na medida em que o estado de ânimo pode ser entendido como aquele decorrente da experiência relacionada às modalidades sensoriais. Uma situação que ocasione uma sensação gustativa agradável ou desagradável pode revelar uma experiência afetiva vivida pela criança. Assim como a sensação gustativa, a organização temporal apresentada pela música, de acordo com Rigg (1964), é a característica mais importante na determinação dos efeitos do estímulo musical sobre o ânimo de um indivíduo. A conseqüência da sensação gustativa experienciada e da música ouvida pode influenciar o estado de ânimo de crianças.

Ojulgamento afetivo do sabor pode ser definido como agradável ou desagradável (Bergamasco \& Beraldo, 1990; Cowart, 1981; Rozin \& Vollmecke, 1986) em decorrência da degustação. A literatura apresenta estudos sobre a sensibilidade humana ao sabor amargo e, geralmente, a conseqüente sensação desagradável que provoca, associada a emoções negativas. Também relata a sensação agradável relacionada a emoções positivas atribuídas ao sabor doce.

Apesar de a literatura, em geral, afirmar que sabores doces estão associados a sensações agradáveis, e sabores amargos, a sensações desagradáveis, mudanças pequenas, embora significativas, podem ocorrer em um curto espaço de tempo na vida de uma pessoa. Devido a essas possíveis alterações, Kimmel, Sigman-Grant e Guinard (1994) justificam a necessidade de testes gustativos com crianças.

Assim como ocorre com o sabor, as pessoas também atribuem significado emocional à música devido às suas características estimuladoras (Gabrielsson \& Juslin, 1996; Giomo, 1993). Para Hevner (1936), a emocionalidade atribuída à música depende também da experiência prévia e do estado de ânimo do ouvinte no momento. E crianças são capazes de interpretar emoções da mesma maneira que os adultos o fazem (Kratus, 1993; Robazza, Macaluso \& D'urso, 1994).

Sabor e música podem ser integrados em um contexto. O sabor, por combinações de atributos sensoriais, é adquirido como resultado da associação com outros estímulos e pode ser determinado por regras culturais e sociais (Mela, 2000). Para North e Hargreaves
(1996), e Terwogt e Van Grinsven (1991), as qualidades eliciadoras dos estímulos musicais interagem com as características contextuais da situação, determinando respostas específicas.

O julgamento das modalidades sensoriais gustativas e auditivas varia, tanto com o contexto em que ocorrem, como também com as atitudes, crenças e expectativas do avaliado (Mela, 2000). Rozin, Riklis e Margolis (2004) explicam que a variação no julgamento resulta de experiências aleatórias, tais como consumir um alimento ruim, ou ouvir notícias boas ou ruins, enquanto se ouve uma música específica. Dentre todas as modalidades que estão interagindo, a modalidade sensorial escolhida para uma tomada de decisão é aquela que domina o processo perceptivo, perante o contexto da tarefa, devido ao significado emocional atribuído ao estímulo (Helene \& Xavier, 2003; Marks, 2003). Ainformação mais acurada será dominante no contexto, sendo então discriminada. Para julgar o motivo ou o estímulo mais influente na tomada de decisão, o indivíduo deve dirigir sua atenção para o seu estado de ânimo, para perceber aquilo que causou o estado de ânimo do momento.

Este estudo pretendeu examinar o julgamento do estado de ânimo realizado por crianças, quando expostas a sensações gustativas associadas ou não a músicas alegres e tristes. Comparou-se o julgamento do estado de ânimo, tanto no contexto de congruência (sabor doce com música alegre; sabor amargo com música triste), como no contexto contrastante (sabor doce com música triste; sabor amargo com música alegre). Objetivou-se também investigar como as crianças de diferentes faixas etárias escolhem a modalidade sensorial causadora do estado de ânimo, diante dos contextos em que os estímulos são congruentes ou contrastantes entre si.

\section{Método}

\section{Participantes}

Participaram do estudo 33 crianças de 5 e 6 anos de idade (média de 5,82 anos), 24 crianças de 7 e 8 anos de idade (média de 7,80 anos) e 26 crianças de 9 e 10 anos de idade (média de 9,86 anos), sendo 45 meninas e 38 meninos, representando uma amostra da população 
de nível social médio-baixo da cidade de São Paulo. 0 protocolo do estudo foi aprovado pelo Comitê de Ética em Pesquisa com Seres Humanos do Instituto de Psicologia da Universidade de São Paulo (CEPH).

\section{Instrumentos}

Os estímulos gustativos utilizados foram sabores doce e amargo representados pelas concentrações supralimiares de $25 \%$ de sacarose (Bergamasco \& Beraldo, 1990) e 0,38\% de cafeína (James, Laing \& Oram,1997) dissolvidas em 1 litro de água destilada; ambas as substâncias foram preparadas em uma farmácia de manipulação. Para cada participante e para cada tipo de solução, foi utilizado um copo descartável.

Primeiramente, a solução de sabor doce foi oferecida à criança, e depois, associada aos quatro trechos musicais. Por volta de meia hora depois, a solução de sabor amargo foi oferecida à mesma criança, e associada aos mesmos trechos musicais. O objetivo era o de examinar cada sabor, separadamente, a fim de controlar possíveis efeitos de um estímulo sobre o subseqüente, e depois, associado aos mesmos trechos musicais. Água filtrada foi utilizada para limpar a impressão gustativa na boca dos participantes durante os testes seqüenciais.

Os estímulos auditivos foram quatro trechos musicais apresentados aleatoriamente, com duração de 18 segundos cada um, reproduzidos em uma fita cassete sem a voz do intérprete. Foram apresentados em um walkman AIWA HS-JS 199 com alto-falante e sem fone de ouvido. Todos os trechos eram categorias de músicas populares diferentes classificados no estudo de Bueno e Macedo (2004) como alegres ou tristes. 0 volume do som foi ajustado de acordo com critérios adequados de audição normal.

Os sabores e os trechos musicais foram avaliados, respectivamente, como gostosos ou não gostosos (os rótulos agradável ou desagradável, que aparecem na literatura, foram substituídos por gostoso ou não gostoso em estudo piloto) e alegres ou tristes, por meio de faces esquemáticas representativas dos estados de ânimos de alegria e tristeza. O participante devia associar a sensação gostosa e o estado de ânimo alegre à face alegre e a sensação não gostosa e o estado de ânimo triste à face triste.

\section{Procedimentos}

Cada participante foi avaliado individualmente em três etapas. Na primeira, houve a experimentação do estímulo gustativo doce ou amargo, após a explicação do procedimento. A criança devia identificar o sabor como doce ou amargo e determinar a sensação gustativa como gostosa ou não gostosa. Em seguida, o participante devia apontar a face esquemática de alegria ou tristeza que representasse a sensação e o estado de ânimo julgado.

Na segunda etapa, foi feita a associação do sabor às músicas, anteriormente avaliadas como alegres e tristes (Bueno \& Macedo, 2004). Pedia-se que a criança prestasse atenção ao gosto doce ou amargo do suco e também à música que iria ouvir. Após cinco segundos de execução da música, a criança devia avaliar se esta era alegre ou triste. Foi estabelecido o tempo de cinco segundos, porque, como asseguram Peretz, Gagnon e Bouchard (1998), os indivíduos necessitam de cerca de dois segundos para reconhecer um padrão de ritmo familiar.

Na terceira etapa o motivo do julgamento do estado de ânimo foi avaliado. Questionou-se, então, sobre a expressão da face esquemática alegre ou triste, se o motivo era devido ao gosto, ou à música, ou ambos. As respostas foram anotadas em um formulário desenvolvido para o experimento.

\section{Resultados e Discussão}

As técnicas estatísticas utilizadas foram a análise descritiva bidimensional e a análise de dados categorizados. Foi realizado um procedimento para a análise dos resultados, considerando-se as variáveis explicativas, a saber, sabor: doce e amargo; faixas etárias: 5 a 6 anos de idade, 7 a 8 anos de idade, 9 a 10 anos de idade; trechos musicais: música alegre 1, música triste 2, música alegre 3 e música triste 4 . Já como variáveis respostas foram consideradas, a saber, sensação gustativa, gostosa e não gostosa, o estado de ânimo, alegre ou triste, e o critério de julgamentos, a música, o gosto ou a música e o gosto (Elian \& Lapa, 2004).

\section{Análise descritiva}

Analisando as respostas referentes à sensação do sabor doce, antes e depois de ouvir as músicas 
alegres, notou-se que houve respostas iguais - sabor gostoso - antes e depois da experiência musical, ou seja, o julgamento não se alterou com a exposição à música nesses casos.

Observando as respostas sobre a sensação ao sabor doce, antes e depois das músicas tristes, notou-se que houve alteração do julgamento de poucas crianças em todas as faixas etárias sob a influência da música triste 2. A Figura 1 ilustra a sensação diante do sabor doce depois da música triste 2 .

A Figura 1 mostra que 9\% das crianças de 5 a 6 anos de idade mudaram seu julgamento diante da música triste 2 , seguidas de $4 \%$ das crianças de 7 a 8 anos de idade e de 12\% das de 9 a 10 anos de idade. Para estas, a sensação gustativa passou de gostosa para não gostosa. Na presença da música triste 4, 15\% dos participantes da faixa de 5 a 6 anos de idade mudaram seu julgamento gustativo, como acima. A grande aceitação de substâncias de sabor doce provocada pela sensação agradável é evidenciada na literatura, podendo justificar o pequeno efeito da música triste sobre a sensação gustativa doce como não-gostosa. Isso corrobora a afirmativa de Lawless (1985) de que a presença de substâncias doces quase sempre aumenta a sensação gustativa agradável.

Diante de todas as músicas, houve comportamento idêntico quanto ao julgamento da sensação do sabor amargo dentro de cada faixa de idade. Os participantes que julgaram o sabor amargo gostoso

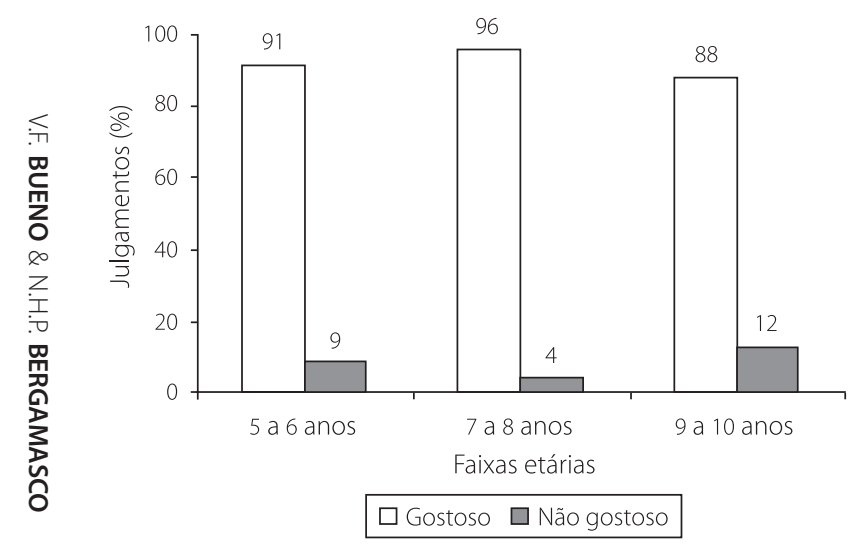

Figura 1. Sensação gustativa diante do sabor doce depois da música triste 2 . antes da exposição às músicas continuaram com o mesmo julgamento depois, o mesmo ocorrendo para os que o julgaram não gostoso. Na faixa etária de 5 a 6 anos de idade, $15 \%$ das crianças consideraram o sabor amargo gostoso. Na faixa etária de 7 a 8 anos de idade, apenas 4\%, e na última faixa de idade, nenhum participante considerou gostoso esse sabor.

Assim como na análise da sensação gustativa, os julgamentos sobre o estado de ânimo associado ao sabor doce foram os mesmos, antes e depois da execução dos trechos musicais alegres, sendo que todas as crianças associaram a esse sabor a face esquemática representativa do estado de ânimo alegre. Nesse contexto, as crianças de 5 a 6 anos de idade escolheram as músicas como determinantes do motivo do julgamento, associando-as a seu estado de ânimo. Lucas (1998), nesse caso, explica que geralmente as crianças de 2 a 7 anos de idade apresentam-se menos interessadas pelos alimentos e mais pelo mundo ao seu redor, nesse caso representado pela estimulação musical.

Já os participantes de 9 a 10 anos de idade julgaram que ambos os estímulos determinam o estado de ânimo. Eles parecem ser capazes de concentrar-se nos estímulos, realizando a síntese das informações. Com o crescimento, as crianças podem ser capazes de isolar as informações e concentrar-se nelas, porque sua capacidade de categorizar, analisar e sintetizar informação está rapidamente tornando-se eficaz e eficiente (De Graaf \& Zandstra, 1999; Liem, Mars \& De Graaf, 2004; Lucas, 1998). No entanto, ao compararmos os dois estímulos, ambos são capazes de influenciar, não havendo um que se saliente sobre o outro. Isso pode demonstrar também a evolução da integração sensorial com o desenvolvimento da criança (Fisher \& Murray, 1991). É como se, para perceber o estado de ânimo, elas necessitassem integrar o estímulo gustativo ao auditivo, para apresentar uma percepção mais coerente.

Considerando ainda o sabor doce, mas agora associado às músicas tristes, observou-se que alguns julgamentos mudaram após essa experimentação. As Figuras 2 e 3 ilustram, respectivamente, o estado de ânimo diante do sabor doce depois das músicas tristes 2 e 4.

Na faixa de 5 a 6 anos de idade, mais de $50 \%$ dos participantes mudaram seu julgamento sobre o estado de ânimo, apontando a face triste após a exposição à 
música triste 2 e a música triste 4 . Na faixa de 7 a 8 anos de idade, $83 \%$ e $75 \%$ alteraram seus julgamentos, respectivamente. Finalmente, na faixa de 9 a 10 anos de idade, $85 \%$ e $81 \%$, respectivamente, tiveram seus julgamentos alterados de alegre para triste após a apresentação da música triste 2 e da música triste 4. Conforme a idade dos participantes, crescem as justificativas a favor do estímulo musical triste como o mais influente no estado de ânimo. Uma possível explicação para esse julgamento é que o estado de ânimo negativo pode intensificar a codificação da informação negativa (Nasby \& Yando, 1982). Nesse contexto, todas as crianças pareceram estar controladas pela negatividade da música.

No contexto do sabor amargo apresentado com as músicas alegres, a maioria dos participantes associou esse sabor à face que manifestava a expressão triste, antes da execução das músicas. As Figuras 4 e 5 ilustram, respectivamente, o estado de ânimo diante do sabor amargo depois da apresentação das músicas alegres 1 e 3 .

Apenas 15\% das crianças de 5 a 6 anos de idade e 4\% das de 7 a 8 anos de idade consideraram o sabor amargo alegre. Após a experiência com a música alegre 1,36\% dos participantes de 5 a 6 anos de idade que associaram o sabor à face triste passaram a apontar a alegre, 52\% dos de 7 a 8 anos de idade fizeram o mesmo, seguidos de $54 \%$ das crianças de 9 a 10 anos de idade.

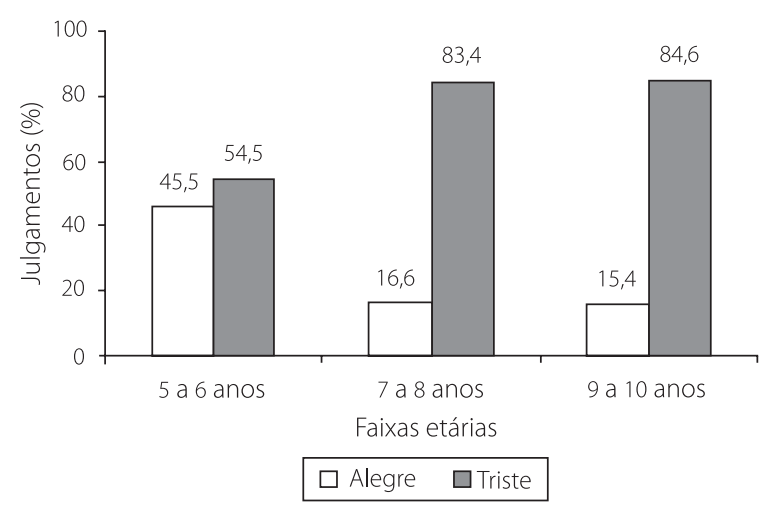

Figura 2. Estado de ânimo diante do sabor doce depois da música triste 2.

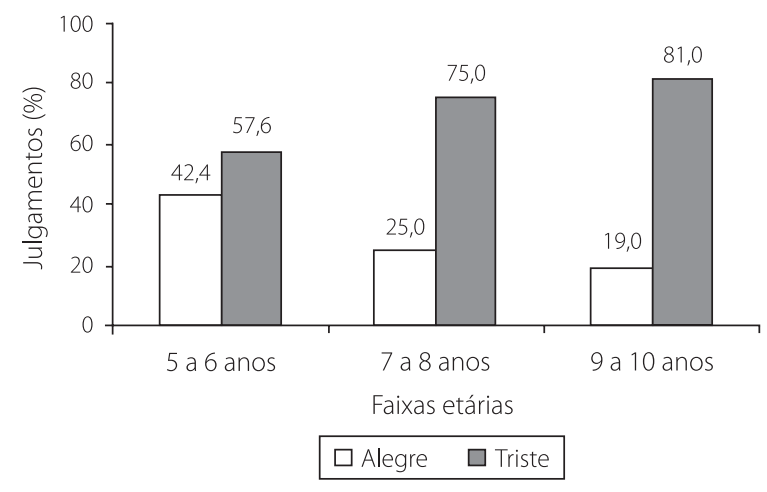

Figura 3. Estado de ânimo diante do sabor doce depois da música triste 4.

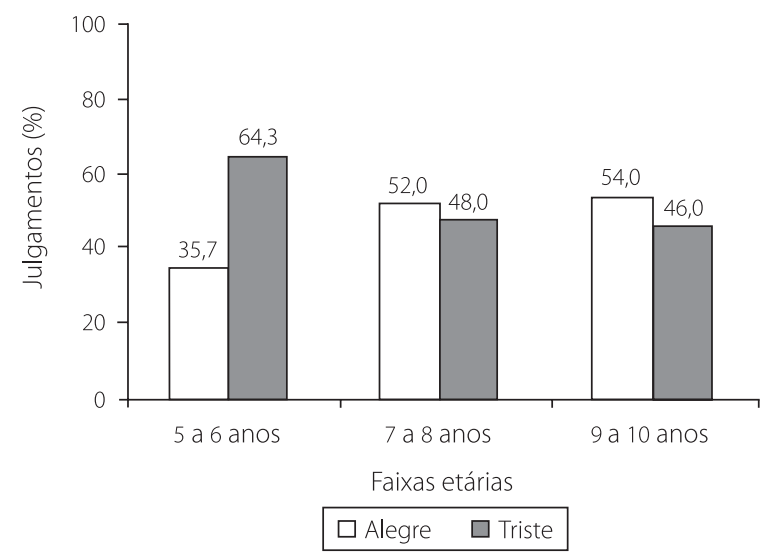

Figura 4. Estado de ânimo diante do sabor amargo depois da música alegre 1.

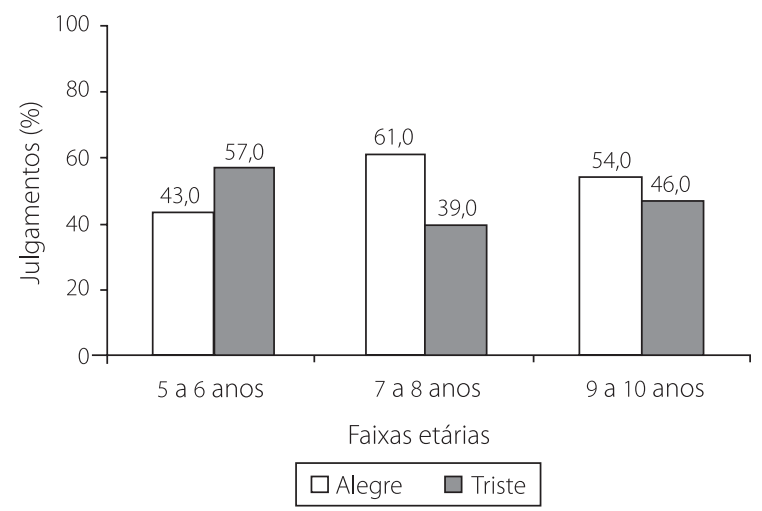

Figura 5. Estado de ânimo diante do sabor amargo depois da música alegre 3. 
Na presença da música alegre 3, na faixa etária de 5 a 6 anos de idade, 43\% passaram a associar a face alegre ao sabor amargo; na faixa de 7 a 8 anos de idade, $61 \%$; e na de 9 a 10 anos de idade, 54\%. Nesse contexto de sabor amargo e músicas alegres, as crianças de 5 a 6 anos de idade parecem ter sido mais influenciadas pelo sabor da solução, como se o estímulo gustativo fosse o mais importante na formação do estado de ânimo. Os participantes mais jovens julgaram o sabor como o mais saliente por, possivelmente, serem altamente sensíveis ao sabor amargo, conforme explica Coelho (2005). Já os participantes a partir dos 7 anos de idade perceberam as músicas alegres como mais influentes, uma vez que, na faixa etária de 7 a 10 anos de idade, há uma queda na sensibilidade ao sabor amargo, de acordo com Coelho (2005). Isso pode também ilustrar uma situação relacionada a alimentos considerados como não gostosos, mas que podem ser julgados como agradáveis quando associados a eventos positivos, no caso, a música.

Não houve alteração de julgamentos com relação ao estado de ânimo referente ao sabor amargo, antes e depois das músicas tristes. Apenas na faixa etária de 5 a 6 anos de idade, 15\% dos participantes associaram esse sabor à face alegre. As crianças que consideraram o sabor amargo gostoso, antes da apresentação das músicas, continuaram com o mesmo julgamento depois. O mesmo ocorreu com aquelas que o julgaram não gostoso. A maioria das crianças considerou o sabor amargo como não-gostoso e o estado de ânimo triste, antes da presença das músicas. A qualificação do amargo como não gostoso sustenta as afirmações de que esse sabor esteja relacionado a emoções tristes e negativas. É também a explicação de Mattes (1994) de que substâncias de sabor amargo ou ácido são mais resistentes a mudanças hedônicas, quando comparadas a substâncias com sabor doce ou salgado. O fato de alguns participantes apreciarem o sabor amargo confirma a idéia de Rozin e Vollmecke (1986) e de Tuorila (1996), de que alguns indivíduos possam se sentir atraídos por sabores que originalmente não são considerados agradáveis pelo senso comum.

As crianças das faixas etárias de 7 a 10 anos de idade associaram o sabor amargo à face triste. Na presença dos trechos musicais tristes, todos os partici390 pantes continuaram a atribuir a mesma face, quando sujeitos ao sabor amargo. Os participantes de 5 a 6 anos de idade justificaram o estado de ânimo triste com o sabor, em primeiro lugar, seguido pela música, sugerindo que a mudança no contexto dos estímulos influencia a tomada de decisão e que não se pode aplicar a explicação de Lucas (1998) como regra geral. No entanto, o fato corrobora a explicação de Coelho (2005) sobre a alta sensibilidade ao sabor amargo de crianças de 4 a 6 anos de idade, tornando-o o estímulo mais saliente e merecedor de sua atenção. Conforme aumenta a faixa etária, há menos justificativas baseadas apenas no sabor e mais apontando para ambos os estímulos. É como se tanto o sabor como a música fossem eleitos estímulos igualmente relevantes para influenciar o estado de ânimo.

\section{Análise inferencial}

A análise inferencial foi realizada para verificar a possível existência de efeito das músicas sobre a sensação gustativa e sobre o estado de ânimo das crianças. Apenas os contextos em que a análise descritiva apontou para um possível efeito da música foram considerados, a saber, sensação gustativa:- sabor doce e músicas tristes; estado de ânimo:- sabor doce e músicas tristes; - sabor amargo e músicas alegres. A faixa etária não foi considerada devido aos pequenos tamanhos de amostra (Elian \& Lapa, 2004).

Analisaram-se os contextos do sabor doce com as músicas tristes, em que não ocorreu manutenção de julgamento após a apresentação das mesmas. Os resultados indicaram que a grande maioria dos participantes manteve o julgamento a respeito do sabor doce $(\hat{p}=0,916)$ após a execução da música triste 2 , com base no intervalo com 95\% de confiança [0,850;0,965].

Para verificar se a proporção do julgamento "gostoso" foi a mesma antes e depois da música, foi feito o teste de igualdade de proporções de McNemar, em que as hipóteses são:

$H_{0}: P($ julgar gostoso antes da música $)=P($ julgar gostoso depois da música);

$H_{a}: P$ (julgar gostoso antes da música) $\neq \mathrm{P}$ (julgar gostoso depois da música). 
A hipótese de igualdade de proporções (nível descritivo=0,0156) foi rejeitada, ao nível de 5\% de significância, ou seja, há diferença entre as proporções de julgamento "gostoso" antes e depois da música triste 2. A estimativa pontual $(\hat{p}=0,084)$ e o intervalo com 95\% de confiança $[0,024 ; 0,144]$ indicaram que a proporção de julgamento "gostoso" antes de ouvir a música triste é maior do que depois. Portanto, pode-se concluir que existe efeito da música triste 2, no sentido de diminuir a proporção de julgamento "gostoso".

Quando foi analisado o contexto do sabor doce e da música triste 4, observou-se que a grande maioria dos participantes também manteve seu julgamento a respeito do sabor doce depois dessa música $(\hat{p}=0,94)$. Comparando-se com a música triste 2, observou-se que, sob o estímulo da música triste 4, a manutenção do julgamento foi um pouco maior. A partir do intervalo com 95\% de confiança $[0,882 ; 0,980]$, estima-se que a proporção de crianças que mantiveram seu julgamento após a execução da música triste 4 é pelo menos 88\%, fato indicativo de inexistência de efeito de música.

O teste de igualdade de proporções de McNemar foi aplicado e, neste caso, a hipótese de igualdade de proporções de julgamento "gostoso" antes e depois da música (nível descritivo =0,0624) não foi rejeitada, ao nível de 5\% de significância. Isso significa que não há evidências para afirmar que houve efeito da música triste 4 sobre a sensação gustativa diante do sabor doce.

Observou-se que, sob o estímulo da música triste 2, tem-se a menor estimativa pontual para a proporção de manutenção do estado de ânimo sob o sabor doce ( $\hat{p}=0,277$ ), e neste estudo estimou-se que essa proporção é no máximo 39\%, com base no intervalo com 95\% de confiança [0,195; 0,386]. Com relação à música triste 4, a estimativa pontual dessa quantidade aumentou um pouco $(\hat{p}=0,301)$, com limite superior de $41 \%$, considerando-se o intervalo com 95\% de confiança [0,216; $0,411]$. Esses fatos são indicativos de efeito das músicas tristes.

A conclusão do teste, ao nível de significância de 5\%, foi a rejeição da hipótese de igualdade de proporções, com nível descritivo menor que 0,001 para as duas situações. No contexto sabor doce e música triste 2 , a estimativa pontual foi de $\hat{p}=0,723$ no intervalo com
$95 \%$ de confiança $[0,627 ; 0,819]$. Com relação ao contexto do sabor doce e da música triste 4, a estimativa pontual foi de $\hat{p}=0,699$ no intervalo com 95\% de confiança. Há, portanto, evidências do efeito dos dois tipos de música influenciando o estado de ânimo das crianças.

Observou-se que, nos contextos do sabor amargo e das músicas alegres, a música alegre 3 teve maior efeito, pois apresenta a menor estimativa pontual para a proporção de manutenção do estado de ânimo diante do sabor amargo ( $\hat{p}=0,518)$, considerando-se o intervalo com 95,0\% de confiança $[0,418 ; 0,629]$, sendo que o máximo valor estimado para essa proporção é cerca de 63,0\%. Sob a música alegre 1, a estimativa pontual aumentou um pouco ( $\hat{p}=0,566)$ no intervalo com 95,0\% de confiança $[0,465 ; 0,674]$, com máximo valor de 67,4\%.

Em ambos os casos, o teste de igualdade de proporções de McNemar foi aplicado. Obteve-se como resultado, a 5\% de significância, a rejeição da hipótese de igualdade de proporções de julgamento "alegre" antes e depois da música. Tanto para a música alegre 1 como para a música alegre 3, o nível descritivo foi menor que 0,001 . No contexto do sabor amargo e da música alegre 3 , a estimativa pontual foi de $\hat{p}=0,482$ no intervalo com $95 \%$ de confiança $[0,374 ; 0,589]$, enquanto no contexto do sabor amargo e da música alegre 3, a estimativa pontual foi de $\hat{\mathrm{p}}=0,434$ no intervalo com $95 \%$ de confiança $[0,327 ; 0,540]$.

Os resultados evidenciaram efeito de ambas as músicas tristes sobre o estado de ânimo das crianças. A inserção da música provocou oscilação no estado de ânimo para negativo, sendo que a música triste 2 mostrou-se mais saliente do que a música triste 4. Já ao comparar as músicas alegre 1 e alegre 3 e o sabor amargo, observou-se que houve efeito de ambas sobre o estado de ânimo, mas a música alegre 3 proporcionou um efeito maior, minimizando o número de julgamentos negativos com relação ao estado de ânimo sob o sabor amargo. Diante destes resultados, que apontam o efeito maior de um estilo musical, pode-se aplicar a explicação de Stratton e Zalanowski (1991), segundo a qual uma pessoa pode desenvolver uma tendência de resposta mais forte a um trecho de música em especial. Isso pode ser atribuído ao fato de que o conjunto de elementos musicais faz com que as pessoas respondam 
de modo distinto à música, como também ao fato de que a experiência prévia dos participantes pode ser capaz de exercer alguma influência sobre o estado de ânimo (Hevner, 1936).

A análise dos motivos dos julgamentos realizados pelas crianças em cada um dos contextos mostrou que, ao ouvir as músicas tristes e experimentar o sabor doce, a maioria delas afirmou ter julgado por influência da música ( $\hat{p} \approx 70 \%)$. A maior influência gustativa nos julgamentos das crianças ocorreu quando este era amargo, sob a música alegre 1 ( $\hat{p} \approx 50 \%)$.

Quando o sabor é doce e a música é a alegre 1, e quando o sabor é amargo e as músicas são tristes, predomina o conjunto sabor e música. A música alegre 3 teve peso um pouco maior do que a música alegre 1 no julgamento dos participantes, como se pôde observar nas duas situações com as soluções.

Quando há contextos contrastantes, isto é, sabor amargo e música alegre ou sabor doce e música triste, de modo geral, o estímulo desagradável predomina na justificativa. A exceção ocorreu apenas no caso de sabor amargo e música alegre 3, provavelmente devido ao maior efeito desta música.

\section{Considerações Finais}

Emoções e sensações podem auxiliar a tomada de decisão devido ao significado afetivo atribuído ao estímulo. Neste trabalho, crianças de faixas etárias diferentes foram capazes de perceber e decidir qual estímulo sensorial foi responsável pelo seu estado de ânimo, no momento em que experimentaram soluções com sabor doce ou amargo, na ausência e na presença de músicas alegres e tristes.

Conclui-se que estudos como este, que analisam a associação de estímulos a estados de ânimo, em crianças de faixas etárias distintas, são importantes porque sugerem que a criança percebe e está atenta tanto ao ambiente como àquilo que sente.

Futuros trabalhos poderiam examinar a autoatribuição do estado de ânimo por crianças diante de tarefas que simulem situações da vida real, como a apresentação de alimentos sólidos associados à

\section{Referências}

Bergamasco, N. H. P., \& Beraldo, K. E. A. (1990). Facial expressions of neonate infants in response to gustatory stimuli. Brazilian Journal of Medical and Biological Research, 23 (3-4), 245-249.

Bueno, V. F., \& Macedo, E. C. (2004). Julgamento de estados emocionais em faces esquemáticas por meio da música por crianças. Psicologia: Teoria e Prática, 6 (2), 27-36.

Coelho, H. D. S. (2005). Avaliação dos limiares de detecção dos gostos doce, salgado, ácido e amargo em pré-escolares e escolares. Tese de doutorado não-publicada, Faculdade de Saúde Pública, Universidade de São Paulo.

Cowart, B. J. (1981). Development of taste perception in humans: sensitivity and preference throughout the life span. Psychological Bulletin, 90 (1), 43-73.

De Graaf, C., \& Zandstra, E. H. (1999). Sweetness intensity and pleasantness in children, adolescents and adults. Physiology \& Behavior, 67 (4), 513-20.

Elian, S. N., \& Lapa, M. G. (2004). Relatório de análise estatística sobre o projeto: efeito do pareamento de sabor e música no estado de ânimo e na agradabilidade do sabor em crianças (RAE-CEA 04P17). São Paulo: IME-USP.

Fisher, A. G., \& Murray, E. A. (1991). Introduction to sensory integration theory. In A. G. Fisher, E. A. Murray \& A. C. Bundy (Orgs.), Sensory integration: theory and practice (pp. 3-26). Philadelphia: FA Davis Company.

Gabrielsson, A., \& Juslin, P. N. (1996). Emotional expression in music performance: between the performer's intention and the listener's experience. Psychology of Music, 24 (1), 68-91.

Giomo, C. J. (1993). An experimental study of children' sensitivity to mood in music. Psychology of Music, 21 (2), 141-162.

Helene, A. F., \& Xavier, G. F. (2003). A construção da atenção a partir da memória. Revista Brasileira de Psiquiatria, 25 (Supl 2), 12-20.

Hevner, K. (1936). Experimental studies of the elements of expression in music. The American Journal of Psychology, 48 (2), 246-268.

James, C. E., Laing, D. G., \& Oram, N. A. (1997). A comparison of the ability of 8-9 years old children and adults to detect taste stimuli. Physiology \& Behavior, 62 (1), 193-197.

Kimmel, S. A., Sigman-Grant, M., \& Guinard, J. X. (1994). Sensory testing with young children. Food Technology, 48 (3), 92-99.

Kratus, J. (1993). A developmental study of children's interpretation of emotion in music. Psychology of Music, $21(1), 3-19$

Lawless, H. (1985). Sensory development in children: research in taste and olfaction. Journal of the American Dietetic Association, 85 (5), 577-585.

Liem, D. G., Mars, M., \& De Graaf, C. (2004). Consistency of sensory testing with 4 - and 5-year- old children. Food Quality and Preference, 15 (6), 541-548. 
Lucas, B. (1998). Nutrição na infância. In L. K. Mahan \& S. Escott-Stump (Orgs.), Krause: alimentos, nutrição e dietoterapia (9a. ed., pp.259-278). São Paulo: Roca.

Marks, L. E. (2003). The role of attention in chemosensation. Food Quality and Preference, 14 (2), 147-155.

Mattes, R. D. (1994). Influences on acceptance of bitter foods and beverages. Physiology \& Behavior, 56 (6), 1229-1236.

Mela, D. J. (2000). Why do we like what we like? Journal of the Science of Food and Agriculture, 81 (1), 10-16.

Nasby, W., \& Yando, R. (1982). Selective encoding and retrieval of affectively valent information: two cognitive consequences of children's mood states. Journal of Personality and Social Psychology, 43 (6), 1244-1253.

North, A. C., \& Hargreaves, D. J. (1996). The effects of music on responses to a dining area. Journal of Environmental Psychology, 16 (1), 55-64.

Peretz, I., Gagnon, L., \& Bouchard, B. (1998). Music and emotion: perceptual determinants, immediacy, and isolation after brain damage. Cognition, 68 (2), 111-141.

Rigg, M. G. (1964). The mood effects of music: a comparison of data from four investigators. The Journal of Psychology, 58 (second half), 427-438.
Robazza, C., Macaluso, C., \& D'urso, V. (1994). Emotional reactions to music by gender, age, and expertise. Perceptual and Motor Skills, 79 (2), 939-944.

Rozin, P., \& Vollmecke, T. A. (1986). Food likes and dislikes. Annual Review of Nutrition, 6, 433-456.

Rozin, P., Riklis, J., \& Margolis, L. (2004). Mutual exposure or close peer relationships do not seem to foster increased similarity in food, music or television program preferences. Appetite, 42 (1), 41-48.

Stratton, V. N., \& Zalanowski, A. H. (1991). The effects of music and cognition on mood. Psychology of Music, 19 (2), 121-127.

Terwogt, M. M., \& Van Grinsven, F. (1991). Musical expression of moodstates. Psychology of Music, 19 (2), 99-109.

Tuorila, H. (1996). Hedonic responses to flavor and their implications for food acceptance. Trends in Food Science \& Technology, 7 (12), 453-456.

Recebido em: 30/10/2006

Versão final reapresentada em: 3/4/2007

Aprovado em: 23/4/2007 